\title{
Assessment of fatality risk in collisions with cable median barriers in the state of Washington
}

\author{
M. H. Ray ${ }^{1}$, C. Silvestri ${ }^{1}$, C. E. Conron ${ }^{1}$ \& R. B. Albin ${ }^{2}$ \\ ${ }^{1}$ Worcester Polytechnic Institute, USA \\ ${ }^{2}$ Washington State Department of Transportation, USA
}

\begin{abstract}
Making effective decisions regarding the use and placement of traffic barriers such as guardrails should be based on an assessment of the risks involved in striking the barrier or interacting with the hazard if the barrier were not there. Unfortunately, it is often difficult to precisely quantify the risk associated with roadside hardware crashes because timely and accurate crash, traffic and inventory information are often not available. An assessment of a particular type of barrier, the cable median barrier, was performed in the US State of Washington to determine the effectiveness of the barrier and quantify the risks associated with the use of the barrier. Data on cable median barrier inventories, traffic characteristics in the subject highway segments and crash histories were obtained. These data were used to calculate the risk of fatal or injurious crashes for both highway sections with cable median barriers and those without. This paper will present the geometric, crash and traffic characteristics that are involved in assessing the risks associated with a collision. Results showing the nature of the risk are presented and recommendations for making design decisions based on the quantification of risk are presented.
\end{abstract}

Keywords: cable barrier, median protection, barrier collision risk.

\section{Introduction}

Median cross-over crashes are some of the most hazardous and difficult to predict types of crashes that occur on highways. When vehicles cross-over to opposing lanes of traffic, the risk of catastrophic injuries is very high since 
vehicles are often striking head-on and drivers in the opposing lanes have little or no warning that a vehicle is coming from such an unexpected direction. There is often little time for evasive actions. Protecting motorists from vehicles crossing over the medians is, therefore, a high priority in providing safe highways.

The objective of this work was to discuss the merits of cable median barrier and its applicability as compared to other types of median crossover protection. The review was completed with the goal of assessing the effectiveness of the cable median barrier system and providing opinions regarding whether WSDOT's use of cable barrier is the best solution for providing reduced crossover accidents, fatalities and severity reduction as compared to concrete or other types of barriers. Crash statistics provided by WSDOT, as well as some evidence from recent crashes were evaluated.

\section{Cable median barrier performance in the state of Washington}

One of the problems with comparing barrier performance from State to State is that each State collects and reports its data differently. Many States do not have good information about the amount and location of their roadside hardware inventory and often it can be difficult to correctly identify cross-over and potential cross-over median crashes based on police reported crash data. Often, States simply resort to reporting the number and percent of cross-median crashes and fatal cross-median crashes without addressing important aspects like traffic growth and installed barrier quantity. While the performance statistics for cable median barriers reported by other States have been consistently good (i.e., cable median barrier effectiveness measure around 95 percent) the data reported in this way is sometimes difficult to interpret (Ray et al [1]).

The best way to compare the performance of traffic barriers is to use crash rates as described in NCHRP Report 490 (Ray et al [2]). A crash rate is calculated by determining the number of crashes in a particular category (e.g., crashes with cable median barriers, cross-median crashes, fatal cross-median crashes, etc.), and dividing by the average yearly traffic volume in the study area and the length of barrier installed in the study area. The resulting crash rate is usually reported in units of crashes per 100 million vehicle miles travelled (100 MVMT). The crash rate is a direct measure of the risk inherent in driving on the road segment. If, for example, the crash rate on a particular one-mile long road segment is 1.00 crashes/100 MVMT, it means that on average one crash occurs for every 100 million vehicles that pass through the one-mile long segment. Put another way, an individual's average risk of being involved in a crash is one in 100 million. Reporting crash statistics in this way allows data from different sites with different traffic volumes and lengths of barriers to be compared directly to each other.

Table 1 shows the crash rates for crashes of all severities, disabling crashes, fatal crashes and disabling and fatal crashes for the periods before cable median barrier was installed and the period after cable median barrier was installed. As shown in Table 1, prior to the installation of cable median barrier, the average 
cross-over fatal and disabling crash rate in the sections where cable barrier was later installed was 0.464 per 100 MVMT whereas after the installation of cable median barriers the rate dropped to 0.118 per 100 MVMT. For fatal crashes, the statewide crash rate prior to the installation of cable median barriers was 0.213 per 100 MVMT and the after rate was 0.044 per 100 MVMT. These rates show that fatal crashes have been reduced by nearly $80 \%$ and fatal and disabling crashes have been reduced by $75 \%$ by the installation of cable median barriers, an impressive improvement in safety.

Table 1: Median cross-over crash rates per 100 MVMT in the State of Washington before and after the installation of cable median barriers.

\begin{tabular}{|l|cc|cc|c|c|cc|}
\hline \multirow{2}{*}{ Segment } & \multicolumn{2}{|c|}{ Total } & \multicolumn{2}{c|}{ Dis abling } & \multicolumn{2}{c|}{ Fatal } & \multicolumn{2}{c|}{$\begin{array}{c}\text { Fatal and } \\
\text { Dis abling }\end{array}$} \\
\cline { 2 - 9 } & Before & After & Before & After & Before & After & Before & After \\
\hline Statewide & 2.009 & 0.607 & 0.251 & 0.074 & 0.213 & 0.044 & 0.464 & 0.118 \\
\hline I-5 Vancouver & 1.238 & 0.176 & 0.146 & 0.117 & 0.291 & 0.000 & 0.437 & 0.117 \\
I-5 Lewis County & 2.983 & 0.351 & 0.213 & 0.000 & 0.426 & 0.000 & 0.639 & 0.000 \\
I-5 Nisqually & 1.126 & 0.000 & 0.000 & 0.000 & 0.375 & 0.000 & 0.375 & 0.000 \\
I-5 Fife & 0.991 & 0.807 & 0.000 & 0.000 & 0.270 & 0.000 & 0.270 & 0.000 \\
I-5 Marys ville & 2.319 & 0.841 & 0.357 & 0.080 & 0.089 & 0.120 & 0.446 & 0.200 \\
I-5 Mt Vernon & 0.861 & 0.000 & 0.287 & 0.000 & 0.287 & 0.000 & 0.574 & 0.000 \\
I-5 Burlington & 4.243 & 0.000 & 1.306 & 0.000 & 0.653 & 0.000 & 1.958 & 0.000 \\
I-5 So. Bellingham & 2.780 & 0.000 & 0.214 & 0.000 & 0.428 & 0.000 & 0.642 & 0.000 \\
I-5 Ferndale & 3.355 & 0.000 & 0.419 & 0.000 & 0.000 & 0.000 & 0.419 & 0.000 \\
I-5 Blaine & 2.256 & 0.000 & 0.000 & 0.000 & 0.000 & 0.000 & 0.000 & 0.000 \\
SR 12 Montesano & 1.682 & 0.000 & 0.420 & 0.000 & 0.000 & 0.000 & 0.420 & 0.000 \\
SR 16 Purdy & 0.000 & 0.000 & 0.000 & 0.000 & 0.000 & 0.000 & 0.000 & 0.000 \\
SR 18 Covington & 2.727 & 0.000 & 0.000 & 0.000 & 0.000 & 0.000 & 0.000 & 0.000 \\
I-90 Iss aquah & 1.778 & 0.000 & 0.000 & 0.000 & 0.000 & 0.000 & 0.000 & 0.000 \\
I-90 George & 3.592 & 0.000 & 0.000 & 0.000 & 0.000 & 0.000 & 0.000 & 0.000 \\
I-90 Moses Lake & 4.989 & 3.648 & 0.000 & 1.216 & 0.454 & 0.000 & 0.454 & 1.216 \\
I-90 E. Moses Lake & 3.838 & 1.856 & 0.426 & 0.000 & 0.000 & 0.000 & 0.426 & 0.000 \\
I-90 Spokane & 3.595 & 1.151 & 0.938 & 0.000 & 0.156 & 0.000 & 1.094 & 0.000 \\
SR 99 Tukwila & 1.291 & 0.000 & 0.000 & 0.000 & 0.000 & 0.000 & 0.000 & 0.000 \\
SR 167 Sumner & 0.319 & 0.000 & 0.000 & 0.000 & 0.000 & 0.000 & 0.000 & 0.000 \\
SR 410 Sumner & 1.489 & 0.000 & 0.000 & 0.000 & 0.000 & 0.000 & 0.000 & 0.000 \\
SR 522 Bothell & 3.989 & 0.000 & 0.000 & 0.000 & 0.000 & 0.000 & 0.000 & 0.000 \\
\hline
\end{tabular}


This trend of reduced cross-median crashes is shown graphically in Figure 1 where the number of fatal and fatal and disabling crashes are plotted by year with the vehicle miles travelled and the miles of cable median barrier installed. In 2000, only about 10 miles of cable median barrier were installed and 18 fatal and disabling crashes occurred, all involving unprotected medians. By 2006 almost 135 miles of cable median barrier had been installed and the number of fatal and disabling collisions had been reduced to five.

The cable median barrier program in Washington State has clearly been effective on a statewide basis. The fatal and disabling crash rate has been reduced by $75 \%$; the barriers are about $95 \%$ effective in containing errant vehicles in the median. The median barrier program on the whole is a success but, as will be discussed below, there are still problem sections where crossmedian crashes persist.

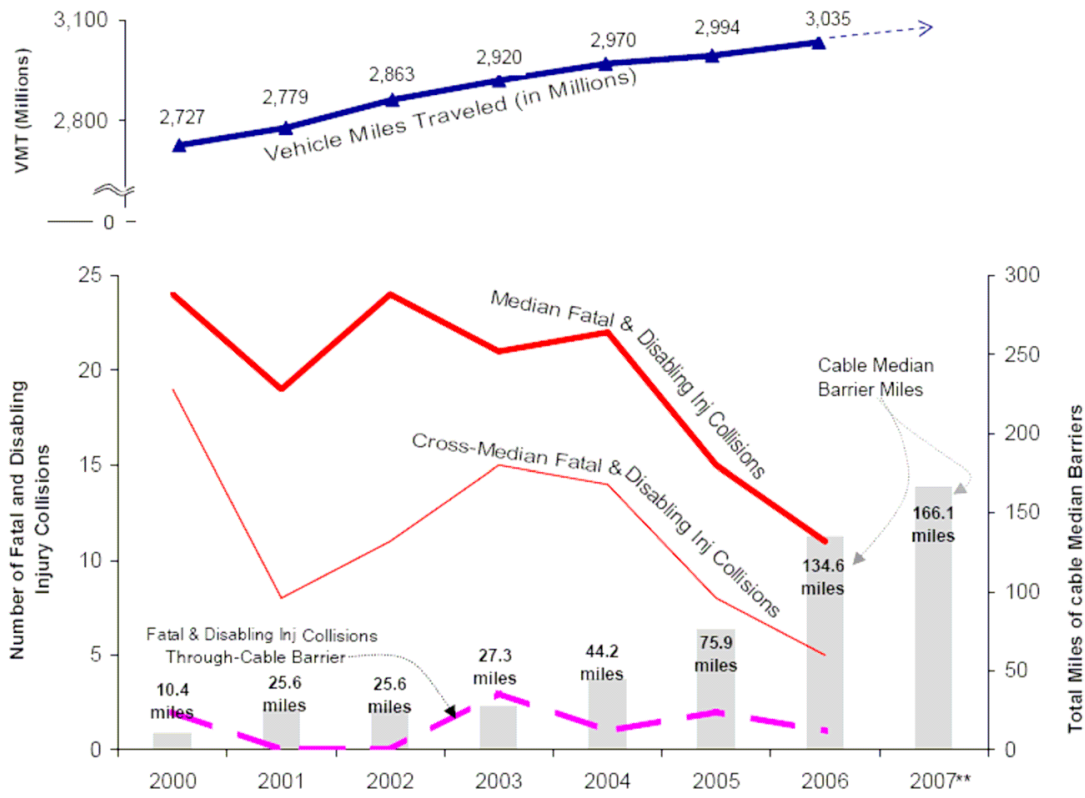

*The data shown within the segments where cable median barriers were installediplanned as of March 2007. Collision data is available through 2006. Vehicle Miles Traveled (VMT) is based on estimated ADT for the segments where cable median barriers were installed as of March 2007.

**166.1 miles of segments where Cable Barriers were installed or in contract as of March 2007

Figure 1: Total miles of cable median barriers installed and cross-median collisions in the State of Washington, 2000-2007 (MacDonald and Batiste [3]). 


\section{$3 \quad$ I-5 in Marysville}

There have been four fatal cross-median crashes where seven people died involving cable median barriers in Washington State since 2000 and all of them have been on the five-mile section of I-5 in Marysville between mile posts 200 and 206. As shown in Table 1, Marysville has the highest fatal cross-median crash rate (i.e., 0.12 fatal crashes/100 MVMT) and second highest fatal and disabling cross-median crash rate (i.e., 0.20 fatal and disabling crashes/100 MVMT) in the state for areas where cable median barriers are installed (Note: I90 near Moses Lake also has a very high fatal and disabling median cross-over crash rate but these are relatively low volume sections of barrier that has not been in place very long so a few crashes have distorted the rate. The rate should approach other values in the state once the number of vehicle miles travelled through the segment increases). While cable median barriers are highly effective in the rest of the state, there is clearly something unusual about I-5 in Marysville.

At issue is the particular nature of this portion of highway. It is significant that all the fatal crashes have been initiated in the southbound direction. Drivers approaching the Smokey Point Rest Area from the north are driving in a rural environment with relatively few interchanges and few traffic conflicts. When these drivers proceed south of State Route 531 they enter the outer edges of the Seattle urban area. Quite suddenly, there is more traffic, there are more vehicles entering and exiting the highway at more numerous interchanges. They may suddenly encounter congestion, slower moving traffic and vehicles trying to merge onto the highway. This type of situation is what creates conflicts between vehicles. These types of in-stream traffic conflicts are almost always the precipitating events in median cross-over crashes.

According to WSDOT traffic data, the traffic volume increases from 79,000 vehicles/day to 111,000 vehicles/day as drivers pass State Route 531, an increase of traffic of $40 \%$. In this 10-mile section, there are five on-off interchanges and one rest area resulting in an average of one interchange every 1.7 miles. Table 2 shows an estimate of the traffic volumes at each interchange based on a 2006 mid-week ramp volume count and the approximate AADT for the areas north and south of State Route 531. The volume flowing southbound doubles between milepost 209 and 199 whereas it is cut in half going northbound. In this one tenmile section, 191,000 vehicles each day are either entering or exiting I-5. The percentage of vehicles merging into the traffic stream is shown in Table 2. Some interchanges have very high percentages of merging vehicles. For example, at the southbound SR531 interchange over half (i.e., 51 percent) of the vehicles are either exiting or entering the highway at that location. All the interchanges southbound, with the exception of the rest area, are above 35 percent. The percentage of vehicles entering and leaving is a measure of how much traffic mixing is occurring. When vehicles are mixing they are merging on-to or off-of the highway, changing lanes, repositioning themselves to accommodate merges and making other lane change manoeuvres. A large amount of traffic mixing will result in a corresponding increase in traffic conflicts, some of which will 


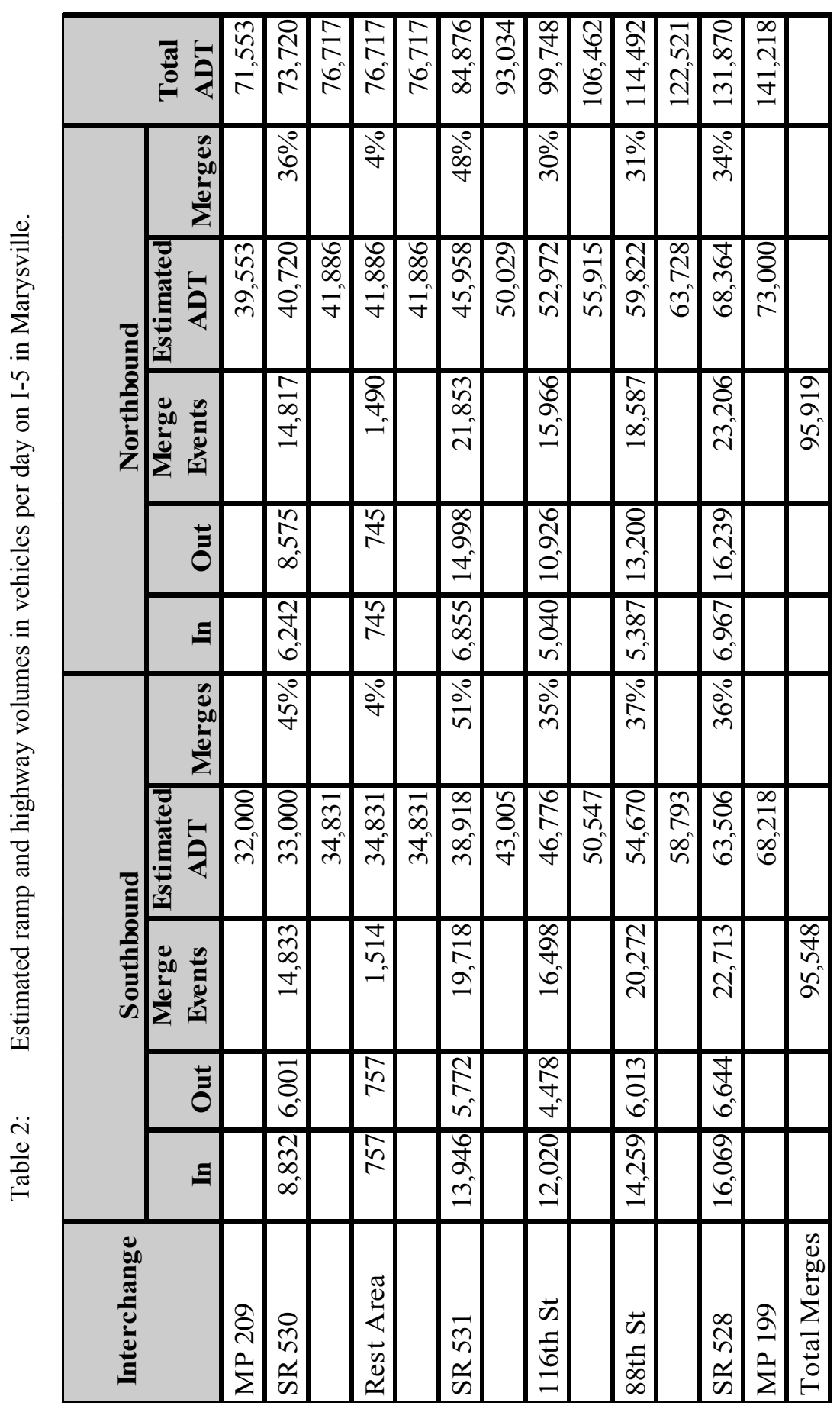


progress into cross-median crashes. The traffic conditions in this segment of I-5 seem to promote cross-median crashes so the barriers are more frequently tested than in other parts of the State where traffic conditions are less demanding.

\section{Cross-over alternatives}

All roadside safety design involves finding the best compromise. No system is $100 \%$ safe, all systems involve trade-offs and every system will fail in some types of impacts. For example, cable median barriers are an attractive alternative because many miles of highway can be effectively treated with a device that has a good track record for safety. The trade-off is that occasionally vehicles may penetrate the barrier and cross-over to the opposing lanes. Concrete barriers, on the other hand, can virtually eliminate cross-over crashes but other types of severe crashes will occur since vehicles will be redirected back into the traffic stream. The added expense of concrete barriers limits the amount of miles that can be installed so the net effect on safety can be limited since appropriations for safety are limited. The question to be answered whenever a highway is designed is what alternative results in the lowest net fatal and disabling injury rate?

Table 3 shows crash rates for concrete median barriers based on crash data from four locations collected for the years 2002 through 2006. Rates were calculated for all median related crashes, cross-median crashes and crashes resulting in an overturn. As shown in Table 3, the fatal and disabling crossmedian crash rate is 0.025 crashes/100 MVMT, a rate almost five times smaller than the corresponding cable median barrier crash rate. Concrete median barriers are clearly effective at reducing cross-median crashes. The counter-point to their effectiveness in cross-median protection is that the fatal and disabling crash rate for all types of concrete median barrier related crashes is 0.288 crashes $/ 100$ MVMT, almost twice the rate of cable median barriers. This means that improved cross-median protection comes at the price of more fatal and disabling crashes in the same direction of travel. This may be acceptable in some situations where the likelihood of a cross-median event resulting in a collision is high as would be the case where there are high traffic volumes in the opposing lanes, but clearly care must be taken in choosing to not treat a median, treat it with a cable median barrier or treat it with a concrete barrier.

Table 3: $\quad$ Crash rates per 100 MVMT for concrete median barriers based on crashes at four locations between 2002 and 2006.

\begin{tabular}{|l|r|r|r|r|}
\hline $\begin{array}{c}\text { Crash } \\
\text { Type }\end{array}$ & \multicolumn{1}{c|}{$\begin{array}{c}\text { All } \\
\text { severities }\end{array}$} & Disabling & Fatal & \multicolumn{1}{c|}{$\begin{array}{c}\text { Fatal and } \\
\text { Disabling }\end{array}$} \\
\hline All & 13.15 & 0.200 & 0.088 & 0.288 \\
\hline $\begin{array}{l}\text { Cross } \\
\text { median }\end{array}$ & 0.276 & 0.025 & 0.000 & 0.025 \\
\hline Overturn & 0.676 & 0.025 & 0.000 & 0.025 \\
\hline
\end{tabular}


One of the advantages of cable median barriers is their low cost in comparison to concrete median barriers. Unfortunately, the funds allocated for highway safety construction projects are not limitless so often choices have to be made about how best to spend a fixed amount of funding. Concrete median barriers cost about two to six times more than cable median barriers depending on the grading requirements, so it is possible to treat two to six times more sites if cable median barrier is used. Choosing between cable and concrete median barriers involves balancing the effectiveness of preventing cross-over crashes with the over-all likelihood of fatal and disabling crashes and the amount of funds available for safety improvements.

\section{Recommendation}

Median protection policy, like all good policy, must not be static and policy makers must be willing to modify and adapt policy. It is essential for a policy to be successful, that a good-faith effort to improve standard designs and policies be made as soon as problems are observed or research on better design alternatives is developed. The following specific policy recommendations are provided based on observations in the state of Washington, in the spirit of improving median cross-over protection policy and thereby creating the safest possible travelling environment.

Policy for median barrier selection should be based on a periodic review of crash history for installed median barriers. Engineering judgment and installation recommendations based on highway geometry should be the first criteria in deciding on locations for median barrier but crash history should also play a role for locations like Marysville where the site geometry are simply not accurate predictors of the magnitude of the cross-median problem. Installation recommendations are suggested in Table 4. These recommendations are based on the crash rate histories reported earlier in Table 1 for cross-median crashes of all severities because we should not wait until someone is killed in a crash to make a decision. Any median cross-over is a potential fatal crash and crash data can be collected more quickly based on crashes of all severities.

Table 4 provides a means of making decisions about when to use a median barrier or not, when to use a cable median barrier and when a concrete barrier is preferable to a cable median barrier. The decision matrix represented by Table 4 involves comparing crash rates to site and traffic characteristics so there is an explicit balancing of risk.

\section{Conclusion}

This paper has presented the results of a study in the US State of Washington that determined the cross-median crash rate for locations where cable median barrier is being used. The crash rates show that on a statewide basis the cable median barrier program has resulted in a $75 \%$ reduction in cross-median crash events. Unfortunately the study also showed that certain sites still continued to experience cross-median crash problems. The likely cause of these persistent 
cross-median crashes relates to the characteristics and land-use of the highway area. Crash rates were also calculated for concrete median barriers and a strategy for selecting median treatment options to minimize fatal and disabling crashes was presented.

Table 4: $\quad$ Median barrier installation recommendations based on historical crash rates.

\begin{tabular}{|c|c|c|}
\hline $\begin{array}{l}\text { Crash Rate } \\
\text { Cross-median } \\
\text { crashes of all } \\
\text { severities per } \\
100 \mathrm{MVMT} \\
\end{array}$ & Site Characteristics & Action \\
\hline Greater than 1.00 & $\begin{array}{ll}-\quad & \text { No median barrier, } \\
\text { - } & \text { 30-ft or wider } \\
& \text { median and } \\
\text { - } \quad 6: 1 \text { or flatter slopes. }\end{array}$ & $\begin{array}{l}\text { Evaluate cost benefit } \\
\text { of using a cable } \\
\text { median barrier. }\end{array}$ \\
\hline Greater than 2.00 & $\begin{array}{l}\text { - } \quad \text { No median barrier, } \\
\text { - } 30 \text { to } 50 \mathrm{ft} \text { wide } \\
\text { median, } \\
\text { - } 6: 1 \text { or flatter slopes, } \\
\text { - } \text { ADT }>75,000 \mathrm{vpd} \\
\text { and } \\
\text { In rural/urban } \\
\text { transition area. }\end{array}$ & $\begin{array}{l}\text { Evaluate cost benefit } \\
\text { of using a double- } \\
\text { run of cable, w- } \\
\text { beam, thrie-beam or } \\
\text { concrete median } \\
\text { barriers. }\end{array}$ \\
\hline Greater than 0.75 & $\begin{array}{ll}\text { - } & 30 \text { to } 50 \mathrm{ft} \text { wide } \\
& \text { median, } \\
\text { - } & \text { Cable median } \\
& \text { barrier, } \\
\text { - } & 6: 1 \text { or flatter slopes, } \\
\text { - } & \text { ADT }>75,000 \mathrm{vpd} \\
& \text { and } \\
\text { - } & \text { In rural/urban } \\
\text { transition area. }\end{array}$ & $\begin{array}{l}\text { Evaluate cost benefit } \\
\text { of replacing a cable } \\
\text { median barrier with } \\
\text { w-beam, thrie-beam } \\
\text { or concrete median } \\
\text { barriers. }\end{array}$ \\
\hline
\end{tabular}

$\uparrow$ Crash rates should be calculated on sections that are at least two miles long and where data is available such that the section has experienced at least 100 MVMT. Crash rates calculated in shorter segments or where there has not yet been sufficient traffic are liable to be inaccurate and overly sensitive to a few early crashes.

\$ Rural/urban transition areas are areas that are characterized by several of the following characteristics:

- Interchanges spaced closer than two miles apart,

- A change in speed limit,

- A large change in ADT (e.g., 30 percent) in a relatively short distance or

- High ramp volumes in proportion to the mainline ADT. 


\section{References}

[1] Ray, M.H., Silvestri, C., Conron, C.E., Mongiardini, M., Experience With Cable Median Barriers in United States: Design Standards, Policies and Performance, Journal of Transportation, American Society of Civil Engineers, Pending.

[2] Ray, M.H., Weir, J.A., Hopp, J.A., In-Service Performance of Traffic Barriers, National Cooperative Highway Research Program Report No. 490, ISBN 0-309-08762-7, National Academy of Sciences, Washington, D.C., 2003.

[3] MacDonald, D.B., Batiste, J.R., Cable Median Barrier Reassessment and Recommendations, Washington State Department of Transportation, 2007. 